This is an Open Access article distributed under the terms of the Creative Commons Attribution 4.0 International License which permits unrestricted non-commercial use, distribution, and reproduction in any medium, provided the original work is properly cited

\title{
THE EFFECT OF TRADITIONAL MUSIC THERAPY ON BLOOD PRESSURE AMONG ELDERLY WITH HYPERTENSION: A LITERATURE REVIEW
}

\author{
Ni Luh Putu Dian Yunita Sari*, Etty Rekawati²
}

1 Magister Student Faculty of Nursing, Universitas Indonesia, Depok, Indonesia.

2 Community Health Nursing Department, Faculty of Nursing, Universitas Indonesia, Depok, Indonesia.

* Correspondence: dianyunitaputu@gmail.com

\begin{abstract}
Elderly as one of vulnerable population has experienced several risk of cardiovascular system disturbance such as hypertension. Hypertension be non communicable disease most suffered elderly in some countries. This literature review aimed at describing the effect of traditional music therapy on blood pressure among elderly with hypertension. This study carried out from databases such as EBSCOhost, Scopus, Pubmed, ProQuest, Science Direct and Sage with limited years of an article published in the last ten years (2008-2018). Fifteen most relevant articles were extracted in this study and found that traditional music therapy provide a positive effect to decrease blood pressure's elderly with hypertension and this finding explained clearly with Roy's Adaptation Model. Traditional music therapy provides a positive effect in lowering blood pressure's elderly with hypertension. This therapy can be given as single intervention or collaboration with other non-pharmacological therapy such as calisthenics, breathing exercises, muscle relaxation, lifestyle modifications and walking-based exercise.
\end{abstract}

Keywords: Blood pressure, elderly, hypertension, traditional music therapy, Roy's adaptation model

\section{Introduction}

World Health Organization (WHO) stated that the proportion of elderly of the world rose two times as much in a span of years 2015 until 2050 from the $12 \%$ become $22 \%$ (1). Elderly population increases led to the emergence of some health problems resulting from a setback for seniors on the physical, psychology and its sociocultural (2). One of the physical set back on a cardiovascular system in elderly is hypertension.

The prevalence of elderly with hypertension was high in some countries like India, Malaysia, China and Iran. The prevalence of ederly in India who suffers from hypertension is $50 \%$ (3). Prevalence of elderly in Malaysia who suffers from hypertension is $58,3 \%$ (4). While, prevalence of elderly in China suffers from 
hypertension is 59,9 \% (5). Elderly in Iran that experienced hypertension even $68 \%(6)$. Hypertension is also became a health problem that most happened in Indonesia's elderly with $63,8 \%$ at the age of 75 years old and upward (7).

High incidence of hypertension in elderly impact in some risk complication such as stroke, myocardial infarction, sudden death, heart of coronary heart disease, heart failure, kidney disease even caused death, needed special attention $(2,8)$. Hypertension basically can be healed by a pharmacological and non pharmacological therapy $(9,10)$. There are negative consequences that is felt by elderly with hypertension that consume antihipertensive drugs such as feel dependence with the drugs, nausea, weakness, pain in the stomach and sleep disorders (11). This condition requires study on another nonpharmacological therapy as a companion to decrease blood pressure and reduce the risk of antihypertensive drug's negative consequences.

One of nursing intervention that can be given is music therapy. However, there have not studies about traditional music therapy yet especially in Indonesia that describe the therapeutic effect for elderly's blood pressure. This condition requires a literature review to have dig even deeper its effect for decrease blood pressure of elderly with hypertension. This paper aimed to describe the effect of traditional music therapy on blood pressure among elderly with hypertension.

\section{Objective}

The study aimed at describing the effect of traditional music therapy on blood pressure among elderly with hypertension.

\section{Method}

Several databases were used including EBSCOhost, Scopus, Pubmed, ProQuest, Science Direct and Sage. The keywords were used including "traditional music therapy" and "blood pressure" and "hypertension" and "elderly". This study limits the number of articles from 2008 to 2018. We extracted fifteen relevant articles after cut off the duplication articles.

\section{Result}

\subsection{Description of studies}

One hundred eighty-six articles from databases were obtained. However, we excluded 171 articles because of the reasons including not relevant to the objectives. Finally, 15 most relevant articles were extracted in this study including 2 review articles, 3 quasi experiment and 10 randomized controlled trial articles. The selected articles in this study were 4 articles from India, 3 articles from China, 2 articles from Turkey, 2 articles from UK, 1 article from Norway, 1 article from Thailand, 1 article from South Korea and 1 article from Australia.

\subsection{Hypertension in elderly}

Hypertension is one of the causes of cardiovascular diseases $(2,4,12)$. Hypertension enforced if someone has blood pressure in over 140/90 $\mathrm{mmHg}$ upon twice measurements in the lapse of time five minutes when at rest and quiet (13). JNC VIII recommended the pharmacological therapy was given if elderly reaches blood pressure in over $150 / 90 \mathrm{nnHg}$ (9). Blood pressure target elderly with hypertension is less than 140/90 $\mathrm{mmHg}(14)$.

Based on a number of literature above it can be concluded that hypertension is one of the health problem that requiring attention in cardiovascular diseases. The classification of hypertension latest consisting of four that is normal, pre hypertension, 
stage-1 hypertension and stage- 2 hypertension. Hypertension in elderly receive pharmacological therapy is recommended for the elderly with blood pressure 150/90 mmHg upward. However, blood pressure under that suggested promote non pharmacological therapy (14).

\subsection{Traditional music therapy}

Music will be therapy for having several therapeutic effects especially on hemispheric brain (15). Music can also affect for decreasing Cortisol then give vasodilatation effect. Genre of music and the pattern of various relating to the production of messenger in the body (16). Culture is a matter of considered in the provision of music therapy for the elderly. Elderly care with cultural sensitive approach is performed on one of the nursing home in Norway give positive impact for elderly's dignity and also give positive impact for elderly's health (17).

One of tradiotional music in India called Kalavati Ragg significantly decrease blood pressure in patients with hypertension with difference of systolic mean $2,74 \mathrm{mmHg}$ after given intervention (18). Turkish classical music also decreases blood pressure in patients with hypertension in a local elderly home in Adana, Turkey. The mean reduction in systolic blood pressure was $13,00 \mathrm{mmHg}$ and the median reductions in diastolic blood pressures were $10 \mathrm{mmHg}$ (19). Turkish Traditional Music or Turkish Sufi as a music therapy decreased the depression level and systolic blood pressure in elderly people in a Turkish nursing home. The mean reduction in systolic blood pressure was 9,68 mmHg (20). Thai instrumental folk music listening was effective for SBP and DBP reduction in stage-2 HT patients in Khon Kaen, Thailand. The mean reduction in systolic blood pressure was $9,50 \mathrm{mmHg}$ and diastolic blood pressure was 6,1 mmHg (21).

Audio relaxation intervention has positive impact to reduce systolic and diastolic blood pressures older adults with hypertension after the 12-session for 6 weeks (22). However, another study state that music have positive impact for blood pressure for elderly when have given twice a week for 8 weeks (23). The provision of music therapy for 30 minutes significantly had an impact on blood pressure's hypertension patients with mean reduction in systolic blood pressure was in $11 \mathrm{mmHg}$ and 13,5 $\mathrm{mmHg}$ in diastolic blood pressure (24). Music has a therapeutic effect to decrease blood pressure when elderly listen for 30 minute every night before going to sleep. Moreover, the tempo of the therapeutic music for elderly with hypertension was 60-80 beats/minute without accented beats, percussive characteristics, or syncopation (25).

The experimental study that held in the Brazil older people with stage-1 hypertension describe that they used active musical experiences, such as improvisation, composition and recreation of songs, and also receptive or passive musical experiences, and activities that included calisthenics and breathing exercises during music therapy (26). Other study also state that the therapies combined music therapy with cognitive reformation, muscle relaxation, and breathing to decrease blood pressure of elderly with hypertension (27). Music therapy combined with lifestyle modifications for three months and significantly reduce blood pressure elderly with hypertension in India (28). Moreover, music combined with walking-based exercise also decrease blood pressure elderly with cardiac rehabilitation for six weeks intervention in Australia (29).

\section{Disscussion}

Roy's Adaptation Model representative to completely underlying intervention in the elderly with hypertension as popolasi vulnerable changed because the aging. Elderly 
had changes in organ functioning, one of them is a function of cardiovascular system such as changing in baroreflect, mechanism hardening of arteries, changing myocardial mechanism and increasing resistance peripheral (2). Physiological changes is affected by risk factors associated with unhealthy lifestyle sparking negative consequences namely hypertension. Roy describes levels of stimulus underlying changes in the individual being three categories such as focal, contextual and residual stimulus (30). A Focal stimulus is a stimulus that emerged suddenly from inside or outside of individual. Focal stimulus in this study is changing in baroreflect, mechanism hardening of arteries, changing myocardial mechanism and increasing resistance peripheral that causes the drop in blood flow to the kidney so there were a mechanism Renin Angiotensin Aldosterone System (RAAS) (2,31). Contextual stimulus is another stimulus that contribute to risk the appearance of focal stimulus, in this study such as is age, sex, race nations and regions residence, family history, consumption of sodium and potassium, consumption of fruits and vegetables, habit of drinking alcohol and smoked, physical activity, body mass index, and psychological stress $(13,30,32)$. While, residual stimulus is a stimulus that it was not immediately clear the impact of the current situation, of in this study such as belief, knowledge, past experience and attitude (30).

A healthy condition according to Roy was someone who could integrate him/herself as a whole ranging from the physical, mental and social aspects. Sick is conditions as someone unable to adapt to stimulus. Input of focal, contextual and residual stimulus who appear making elderly try to control by the regulator and cognator coping. The regulator is coping mechanism associated with the physiological needs. Cognator is coping mechanisms involving cognitive and emotional (30). Nurse for strengthening the coping of regulator and cognator can do intervention and helping the elderly with hypertension is the traditional music therapy, based on the results of previous studies.

Music therapy is one of the nursing interventions that affects spiritual of elderly as evidenced by the results of the qualitative study in the first themes such as "here and now" with meaning statement "music therapy increases my spirit". The fifth theme of this study went on to describe the influence of music therapy to social aspects of the program for the elderly such as "effects of music on care home environment". Caregiver of elderly in this study said that elderly be more cooperative in receiving its therapeutic action and daily tasks after recieve music therapy (33). Traditional music to be the type of music therapy is good to be considered for lowering blood pressure's elderly with hypertension. Caring based on sensitive culture approach better received by elderly as evidenced to research qualitative formerly in the theme "who you are" with the category "music as personal and cultural identity" that explain music therapy conforming to their culture is very meaningful for them (33).

Music therapy also can be combined with other therapy such as calisthenics, breathing exercises, muscle relaxation, lifestyle modifications and walking-based exercise. However, the combination of intervention requires further study to prevent the contradictory effects of cognator and regulator coping mechanism. Another study also showed a positive effect of muscle relaxation program on reducing blood pressure (34). Number of studies suggests the provision of effective music therapy given 6-8 weeks, every day before going to night sleep or just twice a week and for 30 minutes per session. However, Nursing Intervention Classification (NIC) suggested that music therapy well supplied 15 minutes only. This could be referred to the frequencies of music therapy for the elderly with hypertension and strengthen cognator and regulator coping mechanism. 
Strengthening coping mechanism by nurses will affect the effector in the physiological function, self-concept and functions of the role, and interdependency. Physiological function resulting from the strengthening the elderly's coping in independency for oxygenation, nutrition, elimination, activities and sleep and protection needs as well as protection for not having obstructed from hypertension suffered. Self concept and functions of the role resulting from strengthening the spiritual and social aspects of traditional music therapy. Interdependency also closely related to social intercourse with people about that can be generated from a cumulative effect of independence and also a social aspect of the elderly. The final result (output) of nursing care program in this theory is adaptive or maladaptive response of the elderly. The last expected adaptive result in this study is going to decrease blood pressure elderly with hypertension. Adaptation mechanism process is in the scheme below (Scheme 1).

\section{Conclusion and Recommendations}

Elderly as one of vulnerable population has experienced several risk of cardiovascular system disturbance such as hypertension. Some of the negative consequences when consume an antihypertensive drug went further as the basis for a safe and non pharmacological therapy could help to drive down blood pressure, so the use of the drugs could be minimized. Traditional music therapy effective statistically lowering blood pressure's elderly with hypertension described clearly with Roy's Adaptation Model. The next research related combination of traditional music therapy with other non-pharmacological thertapy for elderly required. Further research of the types of traditional music in a country also important to identify traditional music that give therapeutic effect especially for elderly eith hypertension. 


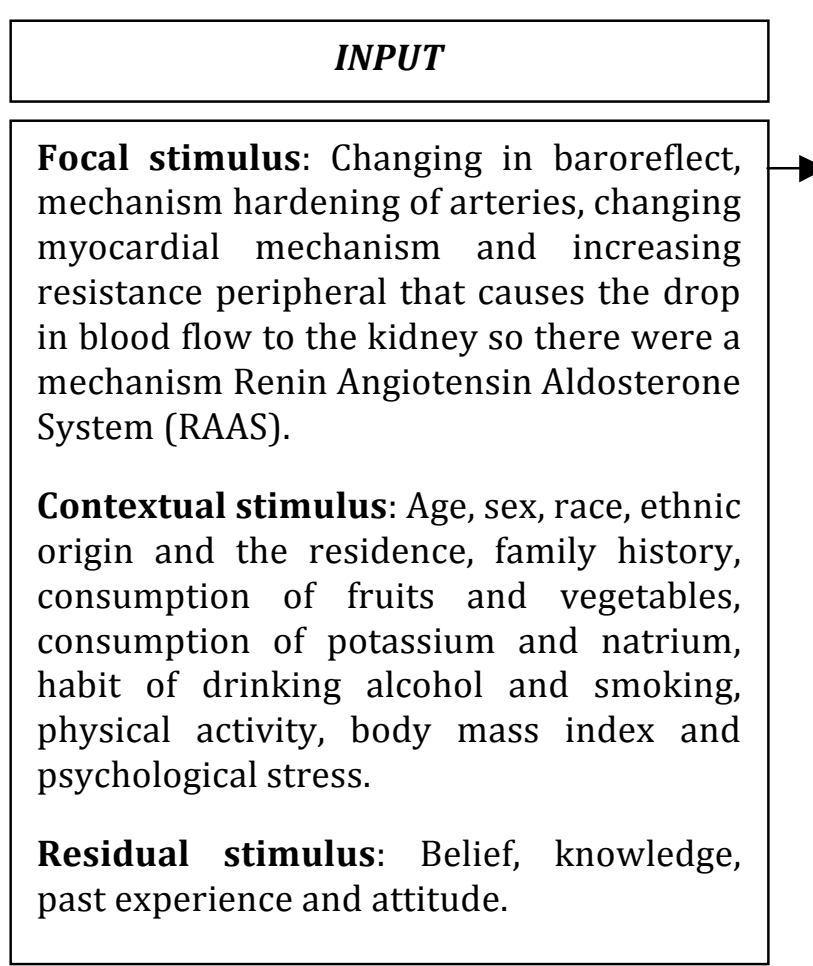

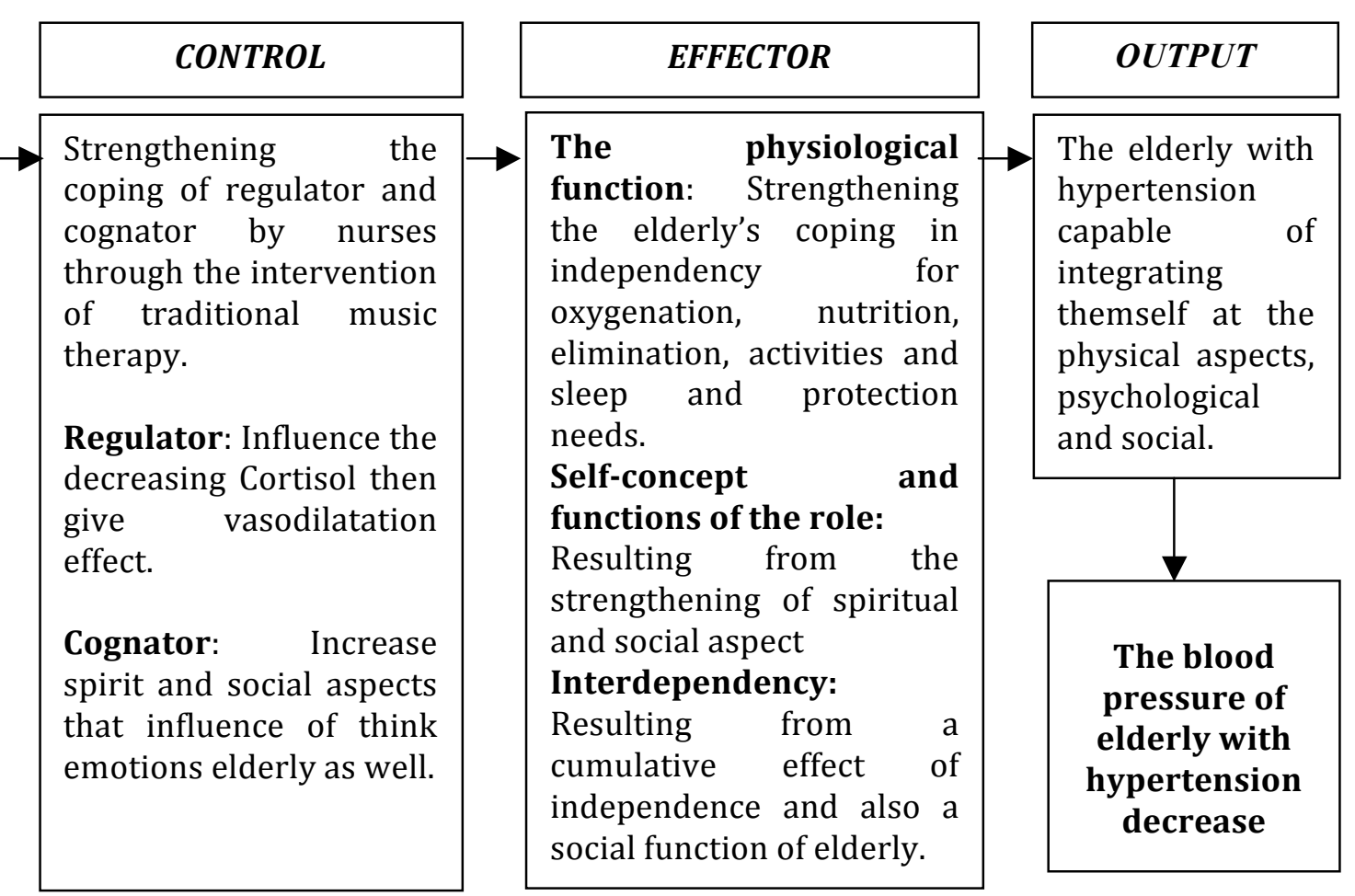

Scheme 1. Modification of Roy's Adaptation Model

Sources: $(2,13,32,34)$ 


\section{References}

1. WHO. World report on ageing and health [Internet]. WHO. Geneva: WHO Library Cataloguing-in-Publication Data; 2015. Available from: apps.who.int/iris/bitstream/10665/186463/1/9789240694811_eng.pdf\%0A\%0A.

2. Miller CA. Nursing wellness in older adults. Philadelphia: Lippincot Williams \& Wilkins; 2012.

3. Alam M, Soni G, Jain K, Verma S, Panda P. Prevalence and determinants of hypertension in elderly population of Raipur city, Chhattisgarh. Int J Res Med Sci [Internet]. 2015;3(3):568. Available from:

http://www.msjonline.org/?mno=176654.

4. Eshkoor S, Hamid T, Shahar S, Ng C, Mun C. Factors affecting hypertension among the Malaysian elderly. J Cardiovasc Dev Dis [Internet]. 2016;3(1):8. Available from: http://www.mdpi.com/2308-3425/3/1/8.

5. Yang ZQ, Zhao Q, Jiang P, Zheng SB, Xu B. Prevalence and control of hypertension among a community of elderly population in changning district of Shanghai: A cross-sectional study. BMC Geriatr. 2017;17(1):1-9.

6. Ghaffari S, Pourafkari L, Tajlil A, Sahebihagh MH, Mohammadpoorasl A, Tabrizi JS, et al. The prevalence, awareness and control rate of hypertension among elderly in northwest of Iran. J Cardiovasc Thorac Res. 2016;8(4):176-82.

7. Kemenkes RI. Situasi lanjut usia (Lansia) di Indonesia [Internet]. Jakarta: Kemenkes RI; 2016. Available from: http://www.depkes.go.id/.

8. Butt DA, Harvey PJ. Benefits and risks of antihypertensive medications in the elderly. J Intern Med. 2015;278(6):599-626.

9. James PA, Ortiz E. JNC 8 hypertension guideline algorithm. Jama. 2014;311(5):50720.

10. Kemenkes RI. Pedoman teknis penemuan dan tatalaksana hipertensi [Internet]. Jakarta: Direktorat Pengendalian Penyakit Tidak Menular; 2013. Available from: http://p2ptm.kemkes.go.id/uploads/2016/10/Pedoman-Teknis-Penemuan-danTatalaksana-Hipertensi.pdf.

11. Shamsi A, Nayeri ND, Esmaeili M. Living with hypertension: A qualitative research. IJCBNM. 2017;5(3):219-30.

12. Currie G, Delles C. Blood pressure targets in the elderly. J Hypertens. 2018;36(2):234-6.

13. Kemenkes RI. Infodatin hipertensi [Internet]. Jakarta: Pusat Data dan Informasi Kementerian Kesehatan RI; 2014. Available from: http://www.depkes.go.id/.

14. Olin BR, Twiggs J, Bell K. Hypertension: The silent killer: Updated JNC-8 guideline recommendations [Internet]. Alabama Pharmacy Association. 2015. Available from: www.aparx.org.

15. Cameron HJ. Long term music therapy for people with intellectual disabilities and the National Disability Insurance Scheme (NDIS). Aust J Music Ther. 2017;28(1):115.

16. Banerjee A, Sengupta R. Music and its effect on body, brain/mind: A study on Indian perspective by neuro-physical approach. iMedPub Journals. 2015;1(2):1-11.

17. Minde G. A culturally-sensitive approach to elderly care. Gerontol Geriatr Res. 2015;4(5):1-5.

18. Varghese J, Joshi M. Effect of music therapy on blood pressure and anxiety in haemodialysis. Int Res J Med Sci. 2015;3(11):1-8.

19. Bekiro T, Ovayolu N, Ergün Y, Hasan C. Effect of Turkish classical music on blood 
pressure: A randomized controlled trial in hypertensive elderly patients. Complement Ther Med. 2013;21(1):147-54.

20. Ugur HG, Aktaş YY, Orak OS, Saglambilen O. The effect of music therapy on depression and physiological parameters in elderly people living in a Turkish nursing home: A randomized-controlled trial. Aging Ment Heal. 2016;1(1):1-8.

21. Im-oun S, Kotruchin P, Thinsug P, Mitsungnern T, Techa-atik P, Pongchaiyakul C. Effect of Thai instrumental folk music on blood pressure: A randomized controlled trial in stage-2 hypertensive patients. Complement Ther Med [Internet]. 2018;39(May):43-8. Available from: https://doi.org/10.1016/j.ctim.2018.05.014.

22. Tang HJ, Harms V, Speck SM, Vezeau T, Jesurum JT. Effects of audio relaxation programs for blood pressure reduction in older adults. Eur J Cardiovasc Nurs. 2009;8(1):329-36.

23. Jeon EY, Kim SY, Yoo HS. Effects of music therapy and rhythmic exercise on quality of life , blood pressure and upper extremity muscle strength in institution-dwelling elderly women. J Korean Acad Nurs. 2009;39(6):829-39.

24. Ezenwa M. Does music therapy reduce blood pressure in patients with essential hypertension in Nigeria? Genet Pathophysiol Essent Hypertens [Internet]. 2015;1(1):89-98. Available from: http://www.intechopen.com/books/geneticsand-pathophysiology-of-essential-hypertension/does-music-therapy-reduceblood-pressure-in-patients-with-essential-hypertension.

25. Chan MF, Chan EA, Mok E, Yuk F, Tse K. Effect of music on depression levels and physiological responses in community-based older adults. Int J Ment Health Nurs. 2009;18(1):285-94.

26. Regina C, Zanini DO, César P, Veiga B, Salgado CM, Cabral M. Music therapy effects on the quality of life and the blood pressure of hypertensive patients. Soc Bras Cardiol. 2008;1(1):1-6.

27. Tang HJ, Harms V, Vezeau T. An audio relaxation tool for blood pressure reduction in older adults. Geriatr Nurs (Minneap). 2010;29(6):392-401.

28. Ubrangala K, Goturu J, Muradi V, Avinash P, Kunnavil R, Doreswamy V. Combination of music with lifestyle modification versus lifestyle modification alone on blood pressure reduction - A randomized controlled trial. Complement Ther Clin Pract. 2015;30(1):1-8.

29. Clark IN, Baker FA, Peiris CL, Shoebridge G, Taylor NF. Participant-selected music and physical activity in older adults following cardiac rehabilitation: A randomized controlled trial. Clin Rehabil. 2016;22(1):1-11.

30. Alligood MR. Nursing theorist and their work. eight. Missouri: Elsevier; 2014.

31. Battegay EJ, Lip GYH, Bakris GL. Hypertension principles and practice. London: Taylor \& Francis; 2005.

32. Pinto IC, Martins D. Prevalence and risk factors of arterial hypertension: A literature review. J Cardiovasc Med Ther 2017 Vol 1 Issue 2 [Internet]. 2017;1(2):7. Available from: http://www.alliedacademies.org/cardiovascular-medicinetherapeutics/

33. McDermott 0 , Orrell M, Ridder HM. The importance of music for people with dementia: The perspectives of people with dementia, family carers, staff and music therapists. Aging Ment Heal [Internet]. 2014;18(6):706-16. Available from: http://dx.doi.org/10.1080/13607863.2013.875124.

34. Pamungkas RA, Kirana W. Relaxation progressive muscle program on exercise behavior and clinical outcomes among hypertension patients. International Journal of Public Health Science (IJPHS). 2016; 5 (4): 400-405 